\title{
Cost Efficiency Analysis of Taiwan Biotech and Pharmaceutical Industry: The Application of Stochastic Meta Frontier Model
}

\author{
Chen-Ming Chen ${ }^{1}$, Tzu-Chun Sheng ${ }^{2} \&$ Yung-Lieh Yang ${ }^{2}$ \\ ${ }^{1}$ Department of Public Finance, Aletheia University, Taiwan, R.O.C. \\ ${ }^{2}$ Department of Finance, Ling Tung University, Taiwan, R.O.C. \\ Correspondence: Tzu-Chun Sheng, Department of Finance, Ling Tung University, Taichung City, Taiwan, \\ R.O.C. Tel: 886-989-997-776. E-mail: morgan1125@teamail.ltu.edu.tw
}

Received: July 18, 2014

doi:10.5539/ijef.v6n11p131

\author{
Accepted: August 19, 2014 \\ Online Published: October 25, 2014 \\ URL: http://dx.doi.org/10.5539/ijef.v6n11p131
}

\begin{abstract}
After the 1980s, Taiwan government has prepared a plan to promote strategies and accelerate the biotechnology development for Taiwan's biotech and pharmaceutical industry. Biotech and pharmaceutical industry technology intensity have a significant connection with the research and development activities and firm performance. Based on the two-step stochastic meta frontier model developed by Huang, Huang and Liu (2012), this study establishes translog cost function. The purpose of the study is to estimate the performance of cost efficiency for firms in the Taiwan biotech and pharmaceutical industry, and to analyze group-specific and firm-specific environmental variables. The empirical results show that it is basically a $15.87 \%$ cost inefficiency for the average cost efficiency of Taiwan biotech and pharmaceutical industry. Firms' operating scale and industrial environment development are supported by the government to encourage cost efficiency. Considering the differences between sub-industries, the empirical results indicate that the $R \& D$ activity promotes the growth of cost efficiency in both pharmaceutical and medical equipment industry. For the relation of agency issues and cost efficiency, Convergence-of-Interest Hypothesis exists in the pharmaceutical industry, and Conflict-of-Interest Hypothesis exists in the medical equipment industry.
\end{abstract}

Keywords: cost efficiency, Stochastic Meta Frontier model, Taiwan biotech and pharmaceutical industry

\section{Introduction}

The biotechnology industry is regarded as the national focus on the development industry. In the 1980s, Taiwan began to focus on future key biotechnology developments. In recent years, the Taiwan government has prepared a plan to promote strategies and accelerate the biotechnology development to strengthen the capabilities and competitiveness of Taiwan's biotech and pharmaceutical industry. Taiwan's government believes that Taiwan offers all the conditions needed for the development of biotechnology, including infrastructure R\&D, finance, human resources and software and hardware facilities. Industrial Development Bureau in Taiwan reports the situation of Taiwan's biotech and pharmaceutical industry. In 2012, Taiwan's biotechnology industry grew $9.4 \%$ to post revenues of US\$8.8 billion, with the medical devices industry accounting for NT $\$ 3.6$ billion, followed by the pharmaceutical industry and applied biotechnology. Taiwan also boasted 1,505 biotechnology firms, employing 69,470 people (data from Biotechnology Industry in Taiwan, 2013). Compared to other advanced countries around the world, Taiwan's biotech industry started late and is mostly made up of small and medium-sized enterprises, facing severe competitive pressures at home and abroad. The operating efficiency of the biotech industry makes them pay extraordinary attention to even the smallest of matters.

People, such as Chen, Hu and Ding (2005), generally believe that the operating performance of the biotech firms still is not very satisfactory and pointed out that most firms in the biotech industry in Taiwan is not only inefficient in terms of the production but also with the production frontier showing a decreasing trend, possibly because overall environmental factors. Yeh, Chen and Chen (2007) and Sheng (2009) also indicate a similar low efficiency evaluation of the biotech industry firms points. Although the overall economic environment is closely related to a firm's performance, we cannot ignore the differences between individual firms which will lead miscalculation of efficiency if taken away. In fact, according to the company's core areas of distinction, the biotech industry covers pharmaceutical and medical equipment, two major fields. Production technology, manufacturer characteristics, and environmental changes of adaptation to the situation vary greatly in different 
fields. If we can address these differences, it should help to correctly assess the biotechnology industry firms operating efficiency.

For this purpose, many studies have discussed the relationship between biotech industry firm-specific characteristics, environment variables and efficiency, such as Chiu, Hu and Tsao (2003), Yeh et al. (2007), Wang and $\mathrm{Lai}$ (2008), $\mathrm{Li}$ and $\mathrm{Li}$ (2008), $\mathrm{Li}, \mathrm{Wu}$ and $\mathrm{Li}$ (2011) and so on. These documents are based on the Battese and Coelli (1995) stochastic frontier model; they use two-stage estimates in their discussion which means that the first stage uses the maximum likelihood estimation (MLE) or the method of panel data estimation to estimate stochastic frontier function inefficiency. The second stage uses estimation inefficiency with environment variables regression analysis.

While the analysis model mentioned above may face efficiency and environment variable related questions are waiting to be overcome, the following documents have discussed this issue, including studies by Keramidou, Mimis and Pappa (2011), Simar and Wilson (2007), De Borger and Kerstens (1996), Battese, Rao and O'Donnell (2004) and O'Donnell, Rao and Battese (2008) and etc. develop meta frontier models to get over the question mentioned above. In practical measuring, meta frontier methods use two stages to begin. The first stage uses a stochastic frontier model to estimate group production frontier for reflecting group technical particularity. The second stage uses the estimate of the group in the first stage of the production frontier and mathematical programming techniques to solve meta production frontiers to reflect the group's technicalities. Obviously, the second stage of the estimated meta frontier, does not have the statistical properties, pursuant to which the estimated efficiency value may not be able to exclude the impact of specific environmental impacts, it is their inadequacies. Recently, Huang et al. (2012) (hereinafter referred to as the HHL model) develop a two-stage stochastic frontier approach to be amended for this problem. The text amendment focuses on the use of a stochastic frontier regression model to estimate the meta frontier, so that the estimated meta frontier with the statistical properties, and offers theoretical basis for regression model discussing technical differences.

This article will use the HHL model constructed by a stochastic meta frontier model, the cost efficiency estimates and compare the 2006-2010 financial data for 52 publicly listed firms of biotechnology and pharmaceutical industry. The industrial classification according to the Directorate-General of Budget, Accounting and Statistics, the biotech industry is divided into the pharmaceutical industry, medical equipment industry group, the use of stochastic regression model to estimate the group cost frontier, meta cost frontier to research topics of discussion. This is the empirical model and the operational efficiency of the biotech and pharmaceutical industry literature.

Biotech and pharmaceutical industry technology intensity have a significant connection with the research and development activities and firm performance. The studies mentioned above regarding operating performance of the firms mostly mention that they have a significant positive relationship between corporate performance and research and development innovation. Then, R\&D are long-term activities, and separate shareholding and management, based on agency problems in the biotechnology and pharmaceutical industries rather than other industries, induced by the relatively high seriousness, and become worthy to address the problem. Relevant literature may adjust the capital structure, such as the manager's stake, to improve the operating performance of the manufacturer; the empirical results are not consistent. In addition, Taiwan's biotech and pharmaceutical industry is an emerging industry, the industry operating environment is in the embryonic stage, firms operating performance by the external environment factors. For example, recently relevant government departments are actively promoting the program in order to lay the foundation for the development of the biotechnology industry. What will the results be for firms operating performance for this series of policy? Are the policy directions adjustments necessary? This deserves attention. Therefore, the above factors and the cost efficiency of the relationship will be the focus of this article.

First in this study, it introduces the basic concepts of the research and bio-technology industry in Section 1; in Section 2, it sets up the framework of the empirical research model, showing the source of empirical data; then following the analysis and comprehensive discussion of empirical results. Section 3 is the main conclusion of this study and proposes future research directions.

\section{Methodology and Model Establishment}

Huang et al. (2012) developed a stochastic meta frontier model (HHL model), set up the translog cost function to estimate the biotech and the pharmaceutical firms efficiency performance, and its empirical analysis of influencing factors. In this part, it will sequence the HHL model, the empirical regression model, and empirical data. 


\subsection{HHL Model}

All decision-making unit (DMU) districts are divided into J groups, the $\mathrm{j}$-the group of $\mathrm{i}$-th DMU (DMUi) stochastic frontier of the group faced at the first period t can be expressed as follows,

$$
Y_{j i t}=f_{t}^{j}\left(X_{j i t}\right) e^{V_{j i t}-U_{j i t}}, j=1,2, \ldots, J ; i=1,2, \ldots, N_{j} ; t=1,2, \ldots, T
$$

Which $Y_{j i t}, X_{j i t}$ respectively output and input in the period t. $f_{t}^{j}(\cdot)$ is the frontier for specific groups, said that the production technology of $\mathrm{j}$-th group at period $\mathrm{t}$, reflecting the certainty part of the production frontier. For example, $f_{t}^{j}\left(X_{j i t}\right)=e^{X_{j i t} \beta_{t}^{j}}, \beta_{t}^{j}$ compared with the $\mathrm{j}$-th group be to estimate the unknown parameter vector. $V_{j i t}, U_{j i t}$ are random error terms, reflecting the random part of the production of frontier. $V_{j i t}$, which is a symmetry error to reflect statistical noise, such as ignoring the variables to measure the output of the error function type selection bias. $U_{j i t}$ is non-negative random variable, reflecting that technical inefficiency. Based on group technology, $\mathrm{DMU}_{\mathrm{i}}$ production technical efficiency can be defined as follows,

$$
T E_{i t}^{j}=\frac{Y_{j i t}}{f_{t}^{j}\left(X_{j i t}\right) e^{V_{j i t}}}=e^{-U_{j i t}}
$$

Unlike Battese et al. (2004) and O'Donnell et al. (2008), the use of mathematical programming techniques to estimate the meta production frontier, HHL, the model is uses stochastic frontier regression model to estimate the meta frontier. Set into the preceding group technology, meta production frontier $\left(f_{t}^{M}\left(X_{j i t}\right)\right)$ as follows,

$$
f_{t}^{j}\left(X_{j i t}\right)=f_{t}^{M}\left(X_{j i t}\right) e^{-U_{j t i}^{M}}, j=1,2, \ldots, J ; i=1,2, \ldots, N_{j} ; t=1,2, \ldots, T
$$

Which $U_{j i t}^{M} \geq 0$ meta production frontier envelopes group technology and reflects the best of the whole industry, thus, $f_{t}^{M}\left(X_{j i t}\right) \geq f_{t}^{j}\left(X_{j i t}\right)$ In theory, when $\mathrm{DMU}_{\mathrm{i}}$ input $X_{j i t}$ will influence the production of $Y_{j i t}$ random error and group technical inefficiency effect are separately taken by $V_{j i t}$ and $U_{j i t} . U_{j i t}^{M}$ reflects group technical and the technology gap ratio (TGR).

Even though the group technology is the most cost efficient, if it transfers into the best technique in the world, then the production will improve very well.

$$
T G R_{i t}^{j}=\frac{f_{t}^{j}\left(X_{j i t}\right)}{f_{t}^{M}\left(X_{j i t}\right)}=e^{-U_{j i t}^{M}} \leq 1
$$

In sum, based on meta technique, production meta technical efficiency $\left(M T E_{j i t}\right)$ of $\mathrm{DMU}_{\mathrm{i}}$ can be defined as follows,

$$
M T E_{j i t}=\frac{Y_{j i t}}{f_{t}^{M}\left(X_{j i t}\right) e^{V_{j i t}}}=T G R_{t i}^{j} \times T E_{i t}^{j}
$$

The relationship between meta technical efficiency $\left(M T E_{j i t}\right)$, group technical efficiency $\left(T E_{i t}^{j}\right)$ and the technology gap ratio ( $T G R_{i t}^{j}$ ) could be described by Figure 1. If we make point A represent the combination of input and output of the $\mathrm{i}$-th firm in the $\mathrm{j}$-th group, then under the condition of output-oriented, $M T E_{j i t}=O B / O D, T E_{i t}^{j}=O B / O C, T G R_{i t}^{j}=M T E_{j i t} / T E_{i t}^{j}=O C / O D$ shows that the three assessment index ranges between 0 and 1 and $M T E_{j i t} \leq T E_{i t}^{j}$. 


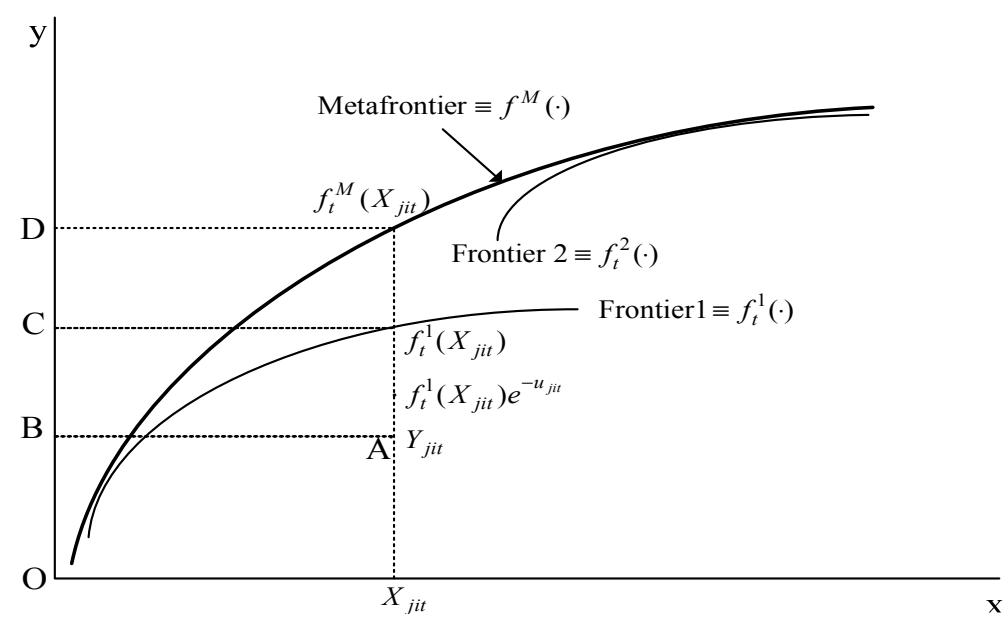

Figure 1. Meta frontier production function

\subsection{Empirical Model}

In this paper, the 52 listed OTC biotech industries and the pharmaceutical field, the firms in the 2006-2010 data sample, use the HHL stochastic meta frontier model and give an empirical analysis of the cost efficiency of Taiwan's biotech industry and the pharmaceutical field.

Compared to similar biotech industry studies and the pharmaceutical efficiency empirical literature, the characteristics of two, firstly, on the basis of the cost meta frontier model, this study highlights characteristics of the biotech industry industrial firms, environmental variables and manufacturer efficiency's relationship. Accordingly, we use the industry classification of the Directorate-General of Budget, Accounting and Statistics; the biotech industry is divided into the pharmaceutical field and the medical equipment field, in order to estimate the cost-effectiveness of the biotech industry firms in group technology and technology performance. Secondly, we use a stochastic frontier regression model to estimate the cost of the meta frontier, the estimated cost frontier with statistical properties. This is different from other large studies that compare meta frontier empirical literature. Therefore, this group cost efficiency model, and meta cost efficiency model are linked in their set up and include two formulas. One functions as a stochastic cost frontier; the second shows the impact on cost efficiency factor. Endogenous variables, including R \& D intensity, and the managers' stake, explain the group cost inefficiency; it then explains the meta cost inefficiency health variables including the firm size, industry concentration and the proportion of the government's shareholding. Use the stochastic cost frontier model of simultaneous estimation for empirical analysis to explore the characteristics of industrial firms of biotech industry, environment variables and manufacturer cost-efficiency.

To sum up, the empirical step is divided into two stages, the first stage is stochastic cost estimating group frontier function and its corresponding cost-effectiveness value of influencing factors; the second stage modify the firms' cost according to the cost inefficiency, then, estimated stochastic meta frontier cost function and its corresponding value of the cost efficiency influencing factors. A proof regression model is expressed in the following.

1) First Stage: Stochastic Cost Group Frontier Function

$$
\begin{aligned}
\ln \left(\frac{C_{i t}}{P_{\text {Lit }}}\right)= & b_{0}+b_{1} \ln \left(\frac{P_{K i t}}{P_{\text {Lit }}}\right)+b_{2} \ln Q_{i t}+\frac{1}{2} b_{3}\left[\ln \left(\frac{P_{K i t}}{P_{\text {Lit }}}\right)\right]^{2}+\frac{1}{2} b_{4}\left(\ln Q_{i t}\right)^{2} \\
+ & b_{5} \ln \left(\frac{P_{K i t}}{P_{\text {Lit }}}\right) \ln Q_{i t}+b_{6} t+b_{7} t^{2}+v_{i t}+u_{i t} \\
u_{i t} & =a_{0}+a_{1} R D_{i t}+a_{2} O S_{i t}+\varepsilon_{i t}
\end{aligned}
$$

2) Second Stage: Stochastic Cost Meta Frontier Function 


$$
\begin{aligned}
\ln \left(\frac{\hat{C}_{i t}}{P_{L i t}}\right)= & b_{0}+b_{1} \ln \left(\frac{P_{K i t}}{P_{L i t}}\right)+b_{2} \ln Q_{i t}+\frac{1}{2} b_{3}\left[\ln \left(\frac{P_{K i t}}{P_{L i t}}\right)\right]^{2}+\frac{1}{2} b_{4}\left(\ln Q_{i t}\right)^{2} \\
& +b_{5} \ln \left(\frac{P_{K i t}}{P_{L i t}}\right) \ln Q_{i t}+b_{6} t+b_{7} t^{2}+v_{i t}^{M}+u_{i t}^{M} \\
& u_{i t}^{M}=l_{0}+l_{1} \ln Q_{i t}+l_{2} H H I_{i t}+l_{3} G O_{i t}+\varepsilon_{i t}^{M}
\end{aligned}
$$

$C_{i t}$ and $\hat{C}_{i t}$ : Respectively represent firm's total cost and adjusted total cost.

$P_{L i t}$ and $P_{K i t}$ : Respectively represent the prices of the input of labor and capital.

$Q_{i t}$ : Represent total output and firm scale in the cost inefficiency factors model.

$v_{i t}$ and $v_{i t}^{M}$ : Represent the $\mathrm{i}$-th random bias item in normal distribution at the $\mathrm{t}$ period. $v_{i t} \sim i i d \mathrm{~N}\left(0, \sigma_{v}^{2}\right)$, $v_{i t}^{M} \sim$ iid $N\left(0, \sigma_{v^{M}}^{2}\right)$.

$u_{i t}$ and $u_{i t}^{M}$ :The $\mathrm{i}$-th inefficient bias item at $\mathrm{t}$ period, represent cost inefficient degree, non-negative truncated normal distribution.

$R D_{i t}$ : Firm's R\&D activity represented by research development density.

$O S_{i t}$ : Agency issue represented by firm's broker shareholding percentage.

$H H I_{i t}$ : Industry competition degree represented by market density.

$G O_{i t}$ : Government's intervention degree represented by government shareholding percentage in a firm.

$\varepsilon_{i t}, \varepsilon_{i t}^{M}:$ Random bias, non-negative truncate normal distribution.

As stated (6) and (8) are respectively the stochastic cost frontier functions of (7) and (9) which represent cost inefficiency factors.

\section{Empirical Results}

This paper uses Frontier 4.1 software to analyze. First, (6) and (7) the group of stochastic cost frontier simultaneous regression equations to estimate the group stochastic cost frontier function and its corresponding cost efficiency and impact factors; amendments to the firms' cost according to the group cost estimate of the inefficiency, according to (8), (9) is the meta stochastic cost frontier simultaneous regression equations used to estimate meta stochastic cost frontier functions, and their corresponding cost efficiency value and impact factors. In this part, each model's parameter estimation results, comparison of firms in five years, the cost of efficiency are indicated.

\subsection{Group Stochastic Cost Frontier Model Estimation Results}

The group stochastic cost of frontier functions and inefficiency of estimated results summarized in Table 1 and Table 2. Table 1 and Table 2 present the pharmaceutical field (Group A) medical equipment field (Group B) and the groups estimated results.

Table 1. Parameter estimates of group A

\begin{tabular}{lcccc}
\hline Variable & Parameter & Estimated Coefficient & Std. Dev. & T-Statistic \\
\hline Constant & $b_{0}$ & $11.6943^{* * *}$ & 0.9925 & 11.7832 \\
$\ln \left(\frac{P_{\text {Kit }}}{P_{\text {Lit }}}\right)$ & $b_{1}$ & 1.1685 & 0.8414 & 1.3887 \\
$\ln Q_{i t}$ & $b_{2}$ & 0.0012 & 0.5891 & 0.0020 \\
{$\left[\ln \left(\frac{P_{\text {Kit }}}{P_{\text {Lit }}}\right)\right]^{2}$} & $b_{3}$ & -0.1012 & 0.1479 & -0.6842 \\
$\left(\ln Q_{i t}\right)^{2}$ & $b_{4}$ & -0.0839 & 0.0972 & -0.8633 \\
\hline
\end{tabular}




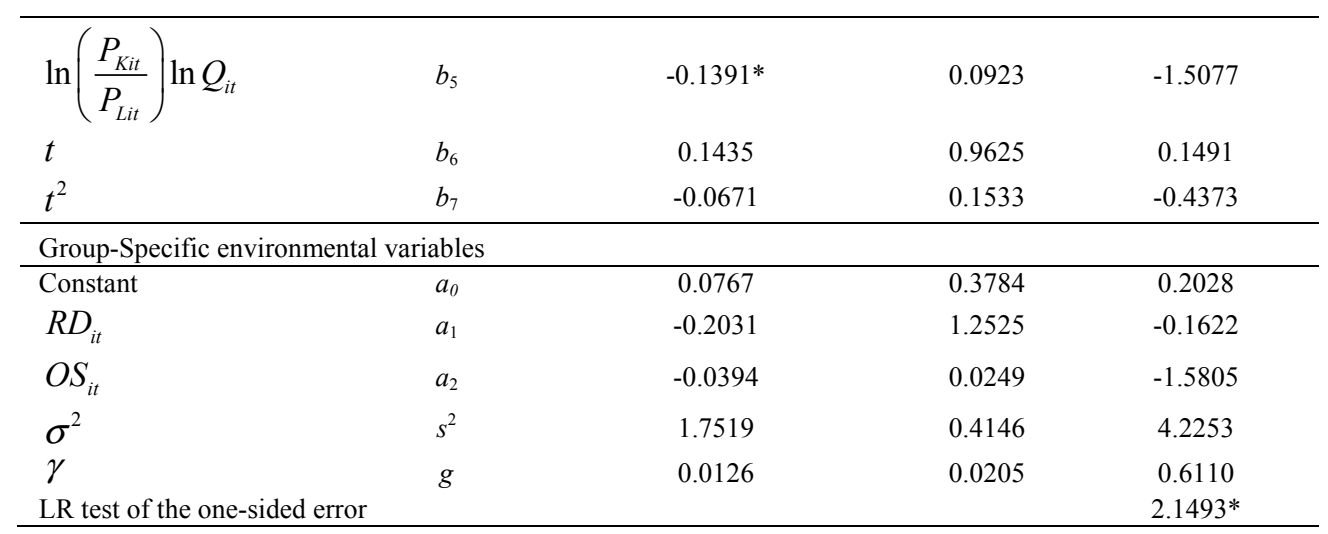

Note. $* * *$ denotes significance at $1 \%$ level; $* *$ denotes significance at $5 \%$ level; $*$ denotes significance at $10 \%$ level.

Overall, the frontier functions of the two groups group stochastic cost and inefficiency of influencing factors is estimated that the results did not show significant differences in the impact direction of the statistically significant test variables. By the estimated results the following can be observed:

1) The relative factor prices and cost of capital and labor inputs are in positive relationship, such as the medical equipment industry. As the relative factor prices caused by raising the cost of the speed is incremented or decremented as a group, but this result is not significant. In this connection, the empirical data, the firms' cost with a factor price increase, is in line with theoretical expectations, but the statistical results cannot clearly point out that the acceleration about how price affect cost.

2) Medical equipment field output cost shows a significant negative correlation. It shows that with all things being equal, firms decreased their costs with the output level increasing. From the quadratic equation we see that an increase in output results in cost reduction at a decreasing rate, but has not been caused by the test of statistical difference. As the empirical regression is constructed as the tranlog type, empirical data reveal that, holding other things consistent, as output increase 1 percent the manufacturer cost approximately decreased by $1.3 \%$.

3) The composite effect of the output and relative factor prices, the pharmaceutical field, Medical, equipment field and cost, present a significant negative relationship.

4) Time changing and cost relationships may reflect the manufacturer's overview of technical changes. The empirical results of the pharmaceutical field's and medical equipment field's time changes and cost relationships show that this five-year study period have no significant changes in technology.

Table 2. Parameter estimates of group B

\begin{tabular}{lcccc}
\hline Variable & Parameter & Estimated Coefficient & Std. Dev. & T-Statistic \\
\hline Constant & $b_{0}$ & $29.6611^{* * *}$ & 1.2423 & 23.8766 \\
$\ln \left(\frac{P_{K i t}}{P_{\text {Lit }}}\right)$ & $b_{1}$ & $3.2752^{* * *}$ & 0.8755 & 3.7411 \\
$\ln Q_{i t}$ & $b_{2}$ & $-1.3017^{* * *}$ & 0.5330 & -2.4423 \\
{$\left[\ln \left(\frac{P_{K i t}}{P_{\text {Lit }}}\right)\right]^{2}$} & $b_{3}$ & 0.0611 & 0.1142 & 0.5349 \\
$\left(\ln Q_{i t}\right)^{2}$ & & & & \\
$\ln \left(\frac{P_{\text {Kit }}}{P_{\text {Lit }}}\right) \ln Q_{i t}$ & $b_{4}$ & -0.0112 & 0.0600 & -0.1871 \\
$t$ & $b_{5}$ & $-0.1866^{* * *}$ & 0.0490 & -3.8072 \\
$t^{2}$ & $b_{6}$ & 0.0643 & 0.4374 & 0.1470 \\
\hline Group-Specific environmental variables & -0.0429 & 0.0714 & -0.6012 \\
\hline Constant & $b_{0}$ & 0.0525 & 0.3132 & 0.1676 \\
\hline
\end{tabular}




\begin{tabular}{lcccc}
\hline$R D_{i t}$ & $a_{1}$ & $-0.3700^{* * *}$ & 0.1053 & -3.5128 \\
$O S_{i t}$ & $a_{2}$ & $0.0218^{* *}$ & 0.0125 & 1.7491 \\
$\sigma^{2}$ & $s^{2}$ & $1.7741^{* * *}$ & 0.2225 & 7.9738 \\
$\gamma$ & $g$ & 0.0000 & 0.0000 & 0.0250 \\
LR test of the one-sided error & & & $15.9503^{* * *}$ \\
\hline
\end{tabular}

Note. $* * *$ denotes significance at $1 \%$ level; ** denotes significance at $5 \%$ level; * denotes significance at $10 \%$ level.

From the impact of manufacturer cost inefficiency degree of regression estimation results can be observed in the following conclusions:

1) Research and development behavior and cost efficiency have a negative correlation, such as in the medical equipment field. On the other hand, the medical equipment field's research and development behavior and cost-effectiveness was positively related. The higher the R\&D intensity, the higher the cost efficiency; on the other hand, if the R\& D intensity is low, the cost efficiency will be lower. Visible R \& D spending to bring the innovation of new products or new technologies, or enhance the level of technology can be effectively applied to enhance cost control or yield, thereby enabling cost efficiency. It is noteworthy that this relationship in the pharmaceutical field has not been through any sort of significant test. Due to reasons that may lie in the pharmaceutical field research and development during the long, backward effect of R\&D investment, the empirical period covers only five years; it still cannot capture any effectiveness. In addition, this may be related to the pharmaceutical field firm scale being relatively small; if the firm is self-developed, the difficulty is so high then they will employ outsourcing such as such as authorized technology transfer to acquires technical knowledge.

2) Manager - The problem of the owner of the agency and the cost inefficiency, depending on the industries. Agency problems with the firms' operating performance relationship has always been the focus of attention of the empirical literature; while there is no consensus arguments can mainly be divided into two areas. The proportion of managerial shareholding and negative operating performance constitutes "plundering" of interests in the relationship; both showed a positive relationship between the interests of convergence "argument. Empirical results and findings of the literature show there is no conclusion due to the characteristics of the industry. The pharmaceutical field manufacturer manager shareholding and cost efficiency presents a significant negative relationship; that is, manufacturer managers hold the highest the percentage, the cost efficiency of the higher; on the contrary, it shows that pharmaceutical field empirical results are the same with the hypothesis "interest convergence". In addition, the manufacturer of medical equipment field managers stake and cost efficiency, showing a significant positive relationship, that means firms' managers hold a higher percentage, is not conducive to the enhancement of cost efficiency; on the other hand, medical equipment field empirical results also fit in with the interests of the looting "hypothesis.

\subsection{Stochastic Cost Meta Frontier Model Estimation Results}

Meta stochastic cost frontier functions and efficiency impact factors are estimated to collate the results in Table 3. With the estimated results the following can be observed:

1) The relative factor prices and cost of capital and labor input showed a significant positive relationship. In other words, with all things being equal, the firms' cost increased with the factor price increase. This fits in with theoretical expectations. The secondary symbol for positive display firms' cost to improve the rate of increase with the factor price increases, but it did not pass a statistical differences test.

2) The composite effect of the output and relative factor prices on the firms cost has a significant negative relationship.

3) Time changing and cost relationships that show changes in the technical effect are not statistically significant, which indicate that within the observation period to the frontier of the meta cost basis there is no significant technological change.

The latter part of Table 3 presents the meta frontier of the firms cost of the benchmark inefficiency. $\left(u_{i t}\right)$ The degree of impact factors of the regression estimation results can be observed with the following conclusions:

1) Firm size has a significant negative impact with cost efficiency, that is on the basis of the cost meta frontier, the larger the manufacturer, the manufacturer is more cost efficient; on the contrary, this empirical data also shows the greater the biotech industry and the size of the pharmaceutical field, the more economies of scale, while enhancing the cost efficiency. 
Table 3. Parameter estimates of meta frontier

\begin{tabular}{|c|c|c|c|c|}
\hline Variable & Parameter & Estimated Coefficient & Std. Dev. & T-Statistic \\
\hline Constant & $b_{0}$ & $10.9314^{* * *}$ & 1.1922 & 9.1691 \\
\hline $\ln \left(\frac{P_{K i t}}{P_{L i t}}\right)$ & $b_{1}$ & $1.3398 * * *$ & 0.4763 & 2.8130 \\
\hline $\ln Q_{i t}$ & $b_{2}$ & 0.2424 & 0.3500 & 0.6924 \\
\hline$\left[\ln \left(\frac{P_{K i t}}{P_{\text {Lit }}}\right)\right]^{2}$ & $b_{3}$ & 0.0043 & 0.0726 & 0.0599 \\
\hline$\left(\ln Q_{i t}\right)^{2}$ & $b_{4}$ & -0.0499 & 0.0458 & -1.0897 \\
\hline $\ln \left(\frac{P_{K i t}}{P_{L i t}}\right) \ln Q_{i t}$ & $b_{5}$ & $-0.0753 * *$ & 0.0438 & -1.7204 \\
\hline$t$ & $b_{6}$ & -0.0456 & 0.3639 & -0.1252 \\
\hline$t^{2}$ & $b_{7}$ & -0.0316 & 0.0599 & -0.5285 \\
\hline \multicolumn{5}{|c|}{ Second-step environmental variables } \\
\hline Constant & $l_{0}$ & $-12.4265 * * *$ & 6.1921 & -2.0069 \\
\hline $\ln Q_{i t}$ & $l_{1}$ & $0.0000^{* * *}$ & 0.0000 & -2.5007 \\
\hline$H H I_{i t}$ & $l_{2}$ & $0.0082 *$ & 0.0059 & 1.3852 \\
\hline$G O_{i t}$ & $l_{3}$ & $-5.9402 * * *$ & 2.5111 & -2.3655 \\
\hline$\sigma^{2}$ & & $16.5581^{* *}$ & 3.9115 & 4.2332 \\
\hline $\begin{array}{l}\gamma \\
\text { LR test of the one- }\end{array}$ & & $0.8890 * * *$ & 0.0320 & $\begin{array}{c}27.7836 \\
66.5329^{* * *}\end{array}$ \\
\hline
\end{tabular}

Note. *** denotes significance at $1 \%$ level; ** denotes significance at $5 \%$ level; * denotes significance at $10 \%$ level.

2) The degree of market concentration has a significant positive impact on the cost inefficiency, which indicates that the higher the overall industry degree of market concentration is not conducive to the firms cost efficiency improvement. This empirical data highlights the increased concentration of the industry market. Firms have strong market power and can circumvent or eliminate competition in the market, with relative lack of incentives and pressure to enhance operational efficiency.

3) Government shareholding with the firms cost efficiency presents a significant negative. That means that the degree of government departments involved in the biotech industry and the pharmaceutical field operation the more they contribute to the improvement of cost efficiency. The biotech industry and the pharmaceutical field in our country is an emerging industry. The firms do not have a long history of development; the scale is relatively small with limited funds, technology acquisition and industrial development and environmental dimensions also being limited. They all need help from government policy intervention. The significance of the empirical results is that through the support of government funding; technology transfers, would help firms operate better, improving cost efficiency, and help the biotech industry construct a foundation.

\subsection{Biotech Industry and Pharmaceutical Field Cost Efficiency Measurement}

In this paragraph the calculation of every indicator in accordance with Table 1, all coefficient estimates in Table 2 and Table 4, and were substituted into the formula (2), (3), in order to calculate the biotech industry and manufacturer group of pharmaceutical field frontier cost efficiency (CE) and meta frontier cost efficiency (MCE) indicators; then, in accordance with (4) computing technology gap ratio. The descriptive statistics of the cost efficiency target values as shown in Table 4, the group cost efficiency index values shown in Table 5.

Listed first in Table 4 is each group's cost efficiency (CE) statistic. Table 4 shows that the average cost efficiency of the firms of the Pharmaceutical field value 0.9310, the average cost efficiency of the firms of Medical equipment field value of 0.9257 . However, with the calculation of these costs and efficiency numbers, there cannot be inter-group comparison. The efficiency of specific group is calculated according technology of specific group, it is nonsense to compare the efficiency between different groups. 
Table 4. Summary statistics of various biotech industry efficiency measures

\begin{tabular}{lccccc}
\hline Group/Statistics & Mean & Median & Maximum & Minimum & Std. Dev. \\
\hline Group A & & & & & \\
CE & 0.9214 & 0.9187 & 1.0000 & 0.8525 & 0.0387 \\
TGR & 0.9205 & 0.9235 & 0.9996 & 0.8265 & 0.0423 \\
MCE & 0.8467 & 0.8462 & 0.8938 & 0.7810 & 0.0166 \\
Group B & & & & & \\
CE & 0.9310 & 0.9364 & 1.0000 & 0.8349 & 0.0456 \\
TGR & 0.8986 & 0.8941 & 1.0000 & 0.8021 & 0.0510 \\
MCE & 0.8345 & 0.8345 & 0.8743 & 0.7488 & 0.0226 \\
Overall & & & & & \\
CE & 0.9257 & 0.9234 & 1.0000 & 0.8349 & 0.0421 \\
TGR & 0.9107 & 0.9090 & 1.0000 & 0.8021 & 0.0476 \\
MCE & 0.8413 & 0.8423 & 0.8938 & 0.7488 & 0.0204 \\
\hline
\end{tabular}

Next, we compare two groups TGR situation. Adopting a meta frontier method to measure manufacturer performance to the cost side, the most important index for judging the technology gap ratio (TGR). Using the TGR value to measure the frontier value of the biotech industry and the pharmaceutical field group stochastic cost is relative to the meta frontier between the cost values of the gap ratio. Its significance lies in that firms have reached the group cost efficiency; but relative to the cost meta frontier, there is still room for improvement. Pharmaceutical field average TGR measure of the value of 0.9205 , medical equipment field average TGR value of 0.8986 , indicating that the cost of frontier of the pharmaceutical field group is relatively closer to the cost meta frontier. However, the medical equipment field TGR maximum value is equal to 1 . The group stochastic cost frontier with the meta frontier costs in the tangent point, implied that the location of sample points is the most efficient. This is indicative of medical equipment field the TGR changes in the degree (the standard deviation of 0.051 ) is relatively more obvious than the pharmaceutical field (the standard deviation of 0.042). Overall, the biotech industry and the pharmaceutical field firms group cost efficiency, cost an average there is still $8.93 \%$ to save space.

Finally, a meta technical basis to observe is the meta cost efficiency (MCE) of the 52 listed biotech firms in Taiwan from 2002 to 2010 value of 0.8413 . That means that there is a $15.87 \%(=1-0.8413)$ cost inefficiency. During the same period, pharmaceutical field's meta cost efficiency (MCE) value of 0.8467 , slightly higher than 0.8345 of medical equipment field.

Going by the data of Table 5 of the pharmaceutical field, medical equipment field group, the value of the cost-efficiency indicators, the following conclusions can be seen:

1) The cost efficiency (CE) value of the pharmaceutical field firms declining trend. If the firms improve the $\mathrm{R} \& \mathrm{D}$ spending, or the use of external pipe technology transfer, and technical knowledge, can effectively reduce the cost inefficiency. Under the "interest convergence" hypothesis, increasing the managers' shareholding will contribute to the improvement of cost efficiency.

2) The medical equipment field firms ' cost efficiency was the potential of going up and down year-by-year. If the firms improve R \& D expenditures they will be able to effectively reduce the cost inefficiency; and lower managerial shareholding ratio will reduce the cost inefficiency in the interests of the looting "hypothesis.

3) In the research period, the meta frontier cost efficiency each year shows that pharmacies are all higher than the medical equipment field. If the manufacturer enhances the scale of operations, then the scale of economics will help to improve the cost efficiency of the biotechnology and pharmaceutical industries. The impact of government policy intervention varies due to the policy content. If we increase "Government shareholding" and help manufacturers overcome capital and technical limitations then we can improve biotech and pharmaceutical field's cost efficiency. Removing market barriers to competition and improving on competitive pressures will promote cost-efficient upgrades. 
Table 5. 2006-2010 Group cost efficiency index

\begin{tabular}{|c|c|c|c|c|c|}
\hline & 2006 & 2007 & 2008 & 2009 & 2010 \\
\hline \multicolumn{6}{|c|}{ Pharmaceutical field } \\
\hline $\mathrm{CE}$ & 0.9248 & 0.9256 & 0.9214 & 0.9151 & 0.9209 \\
\hline TGR & 0.9238 & 0.9148 & 0.9205 & 0.9227 & 0.9210 \\
\hline MCE & 0.8528 & 0.8454 & 0.8467 & 0.8428 & 0.8912 \\
\hline \multicolumn{6}{|c|}{ Medical equipment field } \\
\hline $\mathrm{CE}$ & 0.9322 & 0.9277 & 0.9379 & 0.9174 & 0.9394 \\
\hline TGR & 0.9023 & 0.9033 & 0.8864 & 0.9091 & 0.8912 \\
\hline MCE & 0.8389 & 0.8362 & 0.8295 & 0.8318 & 0.8352 \\
\hline
\end{tabular}

\section{Conclusion}

Based on the two-step stochastic meta frontier model developed by Huang et al. (2012), the study establishes translog cost function. The purpose of the study is to estimate the performance of cost efficiency for the firms in Taiwan's biotech and pharmaceutical industry, and to analyze group-specific and firm-specific environmental variables. Major conclusions are shown below.

1) The empirical results show that it is basically a $15.87 \%$ cost inefficient for the average cost efficiency of Taiwan biotech and pharmaceutical industries.

2) Firms' operating scale and industrial environment development are supported by the government to encourage cost efficiency.

3) Considering the differences between sub-industries, the empirical results indicate that the R\&D activity promotes the growth of cost efficiency in both the pharmaceutical and medical equipment industries.

4) For the relation of agency issues and cost efficiency, Convergence-of-Interest Hypothesis exists in the pharmaceutical industry, and Conflict-of-Interest Hypothesis exists in the medical equipment industry.

\section{References}

Battese, G. E., \& Coelli, T. J. (1995). A model for technical inefficiency effects in a stochastic frontier production function for panel data. Empirical Economics, 20, 325-332. http://dx.doi.org/10.1007/BF01205442

Battese, G. E., Rao, D. S. P., \& O'Donnell, C. J. (2004). A meta frontier production function for estimation of technical efficiencies and technology gaps for firms operating under different technologies. Journal of Productivity Analysis, 21, 91-103. http://dx.doi.org/10.1023/B:PROD.0000012454.06094.29

Chen, M. F., Hu, J. L., \& Ding, C. G. (2005). Efficiency and productivity of Taiwan's biotech industry. International Journal of Biotechnology, 7, 307-322. http://dx.doi.org/10.1504/IJBT.2005.007632

Chiu, Y. H., Hu, J. L., \& Tsao, C. L. (2003). Cost efficiency of biotech firms in Taiwan. Agriculture and Economics, 31, 55-78.

De Borger, B., \& Kerstens, K. (1996). Cost efficiency of Belgian local governments: A comparative analysis of FDH, DEA and econometric approaches. Regional Science and Urban Economics, 26, 145-170. http://dx.doi.org/10.1016/0166-0462(95)02127-2

Huang, C. J., Huang, T. H., \& Liu, N. H. (2012). A new approach to estimating the meta frontier production function based on a stochastic frontier framework. Working Paper.

Keramidou, I., Mimis, A., \& Pappa, E. (2011). Efficiency analysis of sausage industry: Evidence from Greece. African Journal of Business Management, 5(16), 7142-7149.

Li, T. C., Wu, C. W., \& Li, M. C. (2011). An application on stochastic statistical frontier approach and decision tree: Management efficiency analysis of biotechnology industry public listed companies in Taiwan. Paper presented at 2011 Taiwan Productivity and Efficiency, Taipei, Taiwan.

Li, Y., \& Li, S. J. (2008). Analyzing TFP of Asian biotech firms: Application of stochastic frontier approach. Agricultural and Resources Economics, 5(1), 55-76.

O'Donnell, C. J., Rao, D. S. P., \& Battese, G. E. (2008). Meta frontier frameworks for the study of firm-level efficiencies and technology ratios. Empirical Economics, 34, 231-255. http://dx.doi.org/10.1007/s00181-007-0119-4 
Sheng, T. C. (2009). An empirical investigation of the cost efficiency factors and economies/diseconomies of scale effects in Taiwan's biotech-pharmaceutical industry: A stochastic frontier analysis (SFA) approach (Unpublished doctoral dissertation). Northwestern Polytechnic University, California, USA.

Simar, L., \& Wilson, P. W. (2007). Estimation and inference in two-stage, semi-parametric models of production process. Journal of Econometrics, 136, 31-64. http://dx.doi.org/10.1016/j.jeconom.2005.07.009

Wang, C. J., \& Lai, T. S. (2008). The impacts of R\&D, patent and health insurance on firm performance: A research of Taiwan's biotechnology industry. Chaoyang Business and Management Review, 7, 25-48.

Yeh, T. L., Chen, T. Y., \& Chen, C. Y. (2007). On capital structure, ownership and cost efficiency: A case study from Taiwan's biotechnology industry. Taiwan Banking \& Finance Quarterly, 8(3), 45-64.

\section{Copyrights}

Copyright for this article is retained by the author(s), with first publication rights granted to the journal.

This is an open-access article distributed under the terms and conditions of the Creative Commons Attribution license (http://creativecommons.org/licenses/by/3.0/). 